\title{
Study on Application of Smartphone in Mobile Learning of College English under "Internet +" Background
}

\author{
Qian Zhang \\ Luoyang Institute of Science and Technology, Luoyang Henan, 471003, China
}

Key words: "Internet+", Smartphone, College English, Mobile learning, Application.

\begin{abstract}
It beings new mode and new idea for current economic and social development. In short, "internet+" refers to "internet + each traditional industry". It is not just simple combination, but also further improves knowledge, technology, innovative idea, sharing development and talent respect. In daily teaching and learning of college English, the smartphone plays an important role. It is also widely applied in mobile learning of college English. The research on these applications can not just enrich teaching means, but also mobilize students' English learning interest. The final purpose is to improve students' college English learning efficiency. This paper will study the application of smartphone in mobile learning of college English under "internet+" background, in the hope of gaining some experience and enlightenment about college English learning.
\end{abstract}

\section{Introduction}

As technological development, smartphone has become an essential electronic product in life and also deeply influences people's daily life. The appearance of "mobile phone overuse" proves this. People cannot live without smartphone, because smartphone brings convenience to our life and enrich our spare time. Meanwhile, it also helps us do many things. As the State Council issued Instructions on actively promoting action of "internet + " on July 4, 2015, a new pay of "internet + " and knowledge society innovation has been opened. In short, "internet+" refers to "internet + each traditional industry". This does not refer to simple adding, subtracting, multiplying and dividing, but making the best of modern communication technology to bring vitality to each traditional industry. This is an inevitable transformation which results from the development of knowledge society and also the excellent result of continuous development, innovation and practice of modern information technology.

Under the general background of "internet+", the application of smartphone in study increase gradually. It enriches teachers' teaching means and also improves students' learning interest and enthusiasm. The application of smartphone in mobile learning of college English is also very wide, which involves favorable learning mode and suitable application method of smartphone. The investigation and research of smartphone application in mobile learning of college English under "internet+" background is very important for enriching teaching means, improving teachers' teaching ability and method, mobilizing students' college English learning interest. Through smartphone application in mobile learning of college English, students can gain some precious experience and certain enlightenment. Thus, it has far-reaching influence on college English teaching and learning. This paper will carry out empirical study on the combination of "internet $+"$ and college English teaching and especially on the application of smartphone in mobile learning of college English under the general background of "internet+", in the hope of gaining some precious experience and enlightenment. 


\section{general situation of smartphone application in mobile learning of college English}

\section{What is mobile learning}

With technological development, mobile learning as a new word appears in daily learning and teaching. For students, it is a more relaxing and effective learning mode. Meanwhile, it is an important opportunity for teachers to improve their teaching ability and guiding ability for unfamiliar teaching link. What is mobile learning? Just as its name implies, mobile learning is studying during moving. Different from traditional learning mode in fixed space such as classroom or room. Mobile learning refers to learning anytime and anywhere with the help of mobile equipment. Such learning mode needs the help of communication equipment or computer, including smartphone. Thus, the main research content of this paper is the application of smartphone in mobile learning of college English. Mobile learning is bi-directional and interactive learning with the help of modern communication equipment or computer. Under such learning, teachers and students can exchange and learning in two difference spaces. Teachers can complete teaching or instruction after class under such environment. Another kind of mobile learning is one-way teaching with the computer. The teaching resources are entered in the computer in advance, so the resourced may be called for learning anytime and anywhere. In the mode of mobile learning, teaching resources can be shared, and the boundary of time and space is not so obvious. Under "internet+" background, mobile learning conforms to such teaching and learning mode and offers a broader platform for teachers and students.

\section{Definition of smartphone}

The smartphone is data terminal which gradually forms due to the strong user group. Except communication and SMS functions, it also owns effective personal information management function and some functions of computer, such as searching with a browser, video call, voice communication and resource sharing. These functions also let smartphone increasingly close to computer in terms of functions. Meanwhile, the smartphone is also a small-size portable computer. With the birth of various APPs and application software, and continuous optimization of smartphone, mobile learning is more and more widely applied in smartphone and also becomes more and more convenient and effective.

\section{College English learning and application overview of smartphone in mobile learning}

The application of college English learning and mobile learning with smartphone mainly focuses on network resource sharing, APP learning, exchange and learning between teachers' and students, exchange and learning among students and online teaching. These modes are based on resource sharing or expansion of learning scope. As more and more people use smartphone, mobile learning has become a learning trend. An increasing number of teachers and students participate in mobile learning. Hence, the circle of college English learning with smartphone expands. Meanwhile, more teaching resources are concentrated. To learn college English, it is unnecessary to stat in classroom or take books. Mobile learning has met learning demand of teachers and students. Under "internet+" background, college English learning ushers in a new era. The following problems were found in 2015 in the questionnaire survey of 158 college students in the same major about mobile learning of college English. Firstly, the application coverage of smartphone in university campus had reached $100 \%$. Secondly, these students used smartphone every day. 130 students expressed they conducted mobile learning of college English through smartphone, while only 15 of them persisted in learning college English with smartphone. Among the remaining 115 students, 53 students expressed they would learn college English with smartphone twice or three times per week, while the other 62 students would learn college English with smartphone less than twice per week.

During investigating the 130 college students who used smartphone for mobile learning of college English, it was found that most students recited words through smartphone; 55 of them searched words with smartphone; 87 students used mobile APP to recite words; 113 students used network disk or shared college English teaching resources at resource sharing, such as video colloquy, aural comprehension materials and test paper. Thus, the application distribution of smartphone in mobile 
learning of college English is very wide. It was found from interview of these students that, without smartphone, it was very hard to find teaching resources if other colleges or institutions. The smartphone plays an irreplaceable role in aural comprehension dialogue or video, or resource sharing of some training institutions.

\section{"Internet+" and mobile learning of college English}

\section{Application of "internet + " and smartphone}

As everyone knows, "internet+" depends on rapid development of modern information technology. The smartphone as one of new products has its uniqueness in terms of college English learning and application of other products. "internet + " has been proposed in recent years. It complies with the development trend of knowledge society. The application of smartphone in people's life just conforms to such trend. Hence, continuous development of modern information technology facilitates the development of smartphone. In addition, the development of smartphone can better serve people in their life. Such convenience and efficiency are brought under "internet+" background.

\section{"Internet+" and mobile learning}

Under "internet+" background, the requirement for mobile learning just stays on smartphone, computer and network disk. These belong to tool level, while "internet + " brings the help of idea for mobile learning. In terms of resource sharing, "internet+" is a representative. It can share information fast and help more people, while mobile learning also depends on this. In the aspect of innovation idea and talent respecting idea, "internet + " sets a good example to college teachers and students. Mobile learning is an mutual learning process, and teachers and students need to participate in it and communicate together.

\section{How to utilize "internet+" background to improve application of smartphone in mobile learning of college English}

\section{Fully handle resource sharing function of smartphone}

The most convenient point of smartphone application in mobile learning of college English is resource sharing. Information sharing and rapid resource utilization facilitate communication in college English learning. Fully handling resource sharing function of smartphone is not to restrict resource sharing, but to share source under certain preconditions. In this way, rational and effective resource sharing can be ensured, and legal interests of some people cannot be violated.

\section{Fully handle work and rest combination function of smartphone}

Except mobile learning, the smartphone also has recreation and entertainment functions. When the smartphone is used for learning, students are also faced with other lures. Relaxation in good time and combination of work and rest can improve students' learning efficiency and let them relax. Smartphone users should avoid internet addiction and avoid overuse. Thus, teachers and parents should carry out effective guidance and supervision so as to evade the above risks.

\section{Fully handle teachers' guidance of students}

The teacher as the executor of college English teaching should fully grasp the rational points of classroom teaching and mobile learning. Teachers should actively guide students in classroom education and help them make the best of resources in mobile learning. Such teachers are qualified. Teachers also should learn the application of smartphone in mobile learning of college English so as to know students' learning progress and learning difficulties in time. Under "internet+" background, teachers should learn modern information technology and fully tutor students to complete various learning tasks. 


\section{Improve English learning quality with the advantage of "internet+"}

Under "internet+" background, the advantage of modern information technology should be fully utilized. New elements should be actively added in students' English learning to improve students' interest in college English learning. Meanwhile, risks should be avoided. Teachers should give active guidance in learning and prevent improper application of smartphone. It is a good thing that college English teaching owns new information resources, but making the best of these resources is a difficult problem. The society, universities, teachers and students should make joint efforts to utilize the advantage of "internet+" background to improve college English teaching quality.

\section{Conclusion}

Under "internet+" background, college English teaching and learning as well as the progress of knowledge society are connected. The importance and convenience of smartphone for English learning can be seen from smartphone application in mobile learning of college English. Under "internet+" background, colleges should encourage such learning mode, develop mobile learning of English on smartphone and bring more courses in such learning progress to save campus resource, efficiently share resources and exchange. "Internet + " is an inevitable product in the development of knowledge society and also the crystal of human knowledge and experience. These should be closely connected with college education. "Internet + " is also a new opportunity for teachers and students to improve their teaching and learning level. In future college teaching, mobile teaching of college English is a precious trial and experience. It has enlightening role for other disciplines. Chinese education and talent training will certainly have a bright future, if modern information technology develops well under "internet+" background and modern information technology is combined with teaching and learning.

\section{Acknowledgement}

Soft science project of Science and Technology Agency of Henan Province: study on application of smartphone in mobile learning of college English under "internet+" background (project No.: 142400411422)

\section{References}

[1] Wu Hongmei, Study on senior high school English learning mode, Southwest University, 2013 (04).

[2] Hu Jing, Study on application of smartphone-based mobile learning in independent learning of college English, Journal of Huaihua University, 2014 (04).

[3] Diao Meng, Design and implementation of college English listening learning system based on Android platform, Shaanxi Normal University, 2013 (05).

[4] Xia Zengliang, Application and exploration of smartphone-based mobile learning in college English learning, Journal of Hubei Correspondence University, 2013 (03).

[5] Liu Yanrong, Research on smartphone-based mobile learning platform for college English, He'nan Normal University, 2012 (05).

[6] Wang Jing, Study on smartphone-based mobile learning of college English, Journal of Higher Education, 2015 (12). 